\title{
AC 2012-5279: MIDDLE AND HIGH SCHOOL TEACHER PROFESSIONAL DEVELOPMENT
}

Dr. Keith A. Schimmel, North Carolina A\&T State University

Keith Schimmel is an Associate Professor of chemical engineering, Chair of the Energy and Environmental Systems Department, and Deputy Director of the NOAA ISET Cooperative Science Center.

\section{Dr. Muktha Jost, North Carolina A\&T State University}

Muktha Jost is Associate Professor and Coordinator of the online graduate program in Instructional Technology. She has served as a teacher educator for 14 years.

\section{Dr. Tyrette Sherlone Carter, North Carolina A\&T State University}

Tyrette S. Carter's research interests include how to improve the teaching and learning of mathematics, specifically algebra and algebraic reasoning. She has published articles on the Conceptual Context that Promotes Algebraic Reasoning and Questioning and Informational Texts: Scaffolding Students' Comprehension of Content Areas, and she has conducted professional development workshops to support the teaching and learning of mathematics. These workshops involve supporting the use of technology and family involvement. She currently trains pre-service and in-service teachers on how to utilize formative assessment and effectively implement teaching strategies to support students' needs. Her goal is that by training teachers to develop a deeper understanding and motivation for their subject matter, this will increase the number of students who take higher level mathematics courses and pursue careers in mathematics and the sciences.

\section{Mrs. Shawn Raquel Watlington, North Carolina A\&T State University}

Shawn Raquel Watlington is Director of K-20 Engagement \& Professional Development within the NC A\&T Office of University Outreach, where she is responsible for developing and implementing K-12 youth, teacher professional development, and parent/community events.

Ms. Terrie Ruth McManus, Ragsdale High School, Guilford County Schools

Terrie Ruth McManus is an earth/environmental science teacher at Ragsdale High School in Jamestown, N.C. Prior to moving to the Greensboro area, she was a lab instructor at NC State University where she received bachelor degrees in geology and science education, plus a M.S. from the Marine, Earth, and Atmospheric Sciences Department.

\section{Prof. Solomon Bililign, North Carolina A\&T State University}

Solomon Bililign is a professor of physics at North Carolina A\&T State University and is the current Director for NOAA-ISETCSC.

\section{Dr. Terry White Worrell, Guilford County Schools}

Terry White Worrell is a successful educational leader for more than 30 years in urban school districts and a specialist in turning around low-performing schools and creating alternative high schools.

\section{Prof. Yuh-Lang Lin, North Carolina A\&T State University}

Yuh-Lang Lin is a professor at NC A\&T State University. 


\title{
Middle and High School Teacher Professional Development Through University Research Experiences and Curriculum Development
}

\begin{abstract}
A professional development model for middle and high school STEM teachers has been developed, implemented over two years, and assessed. The model involves a partnership between the middle and high school teachers and administrators, education graduate students and faculty, STEM graduate students and faculty, and a NOAA research center. The highlight of the teacher experience was a three week intensive Summer Research Institute in which teachers developed modules connected to Earth systems science research, NASA research, and North Carolina science and mathematics standards-based curricula. Twenty high school science and mathematics teachers from the Central Region of Guilford County Schools participated in the Institute both summers. This arrangement provided an opportunity for the teachers to explore together how STEM concepts can be integrated between mathematics and science courses. During the second summer, the high school teachers served as mentors for twenty middle school science and math teachers from the same school district region. This arrangement provided an opportunity for the teachers to explore together how STEM concepts are taught and understood by students as students matriculate from middle to high school STEM classes. Web 2.0 technologies were demonstrated and utilized. The professional development model was assessed through surveying and focus group interviews with the participants along with evaluation of the curriculum developed.
\end{abstract}

\section{Introduction}

In 2000, the National Commission on Mathematics and Science Teaching for the 21st Century emphasized the importance of high quality math and science instruction to the nation's economic health and made specific recommendations to meet that need, including the establishment of summer institutes, exemplary professional development, good leadership training, and incentive programs to make the teaching profession more attractive. ${ }^{7}$ The math and science teacher professional development model discussed herein seeks to impact national K-12 science and math teaching challenges through the utilization of NASA resources.

The Guilford County School (GCS) district, like many districts across the nation, is culturally diverse (40\% African-American, 8\% Hispanic, 40.4\% White, 5.3\% Asian, 4.6\% Multi-Racial; 86 languages) and economically diverse (48.52\% free/reduced lunch). Specifically, the Central Region of the district struggles to increase its science and math proficiency $\left(8^{\text {th }}\right.$ grade science $62 \%$, Algebra I $38.7 \%$, Physical Science 44\%). The challenge to the district is to prepare high performing students during their high school experience for careers in STEM fields while also engaging all students in exciting math and science education. Additionally, the critical middle school years need to be addressed to increase the pipeline of students entering high school with strong math and science backgrounds.

The science and math teacher professional development model presented herein seeks to address gaps in these programs that have been identified by the National Research Council (2008). ${ }^{5}$ The needs identified that are addressed in the proposed model include effective partnering of K-12 teachers, K-12 administrators, parents, university faculty with NASA science expertise, 
curriculum development experts, professional development experts, evaluation experts, and NASA scientists; use of quality instructional materials with linked professional development; leveraging of resources to provide whole-school STEM reform; long term teacher professional development; effective use of the latest technology; increasing student awareness of the environment from a scientific viewpoint; and development of curriculum materials that specifically target high school students and include engineering content while helping students and teachers to meet local educational goals.

\section{Pedagogy}

The National Science Foundation's Local Systemic Change in Mathematics and Science Programs stresses the importance of the use of quality instructional materials with linked professional development. ${ }^{6}$ The evaluation of this program found that extensive use of even first rate instructional materials was effective only when linked to professional development targeted at teachers' practice, investigation, problem-solving, and instruction. ${ }^{1}$ Sustained engagement with teachers over an extended period of weeks or months is required to effect lasting change in instruction and strengthen teachers' confidence in their knowledge and teaching of science content. ${ }^{4}$ These findings formed the basis for the teacher professional development model used in this study.

Two challenges in designing activities to "inspire and engage" are to attend to what is needed to translate initial excitement into a meaningful learning experience and a sustained, long term interest and to support teachers in providing appropriate follow-up activities for an initial activity. The National Science Education Standards suggest that "effective science curriculum materials are developed by teams of experienced teachers, scientists, and science curriculum specialists using a systematic research and development process that involves repeated cycles of design, trial teaching with children, evaluation, and revision." 5 The module development activities later described are grounded in this principle.

Innovative integration of NASA STEM content into the curriculum modules will not only strengthen the existing course content but will also act as a stimulus for the engagement of students to provide relevance of their classroom learning to the practical applications of NASA research. Our past experiences and educational research indicate such relevance is influential in attracting and retaining students (in particular underrepresented minorities) in STEM

disciplines. ${ }^{2,3,8}$ Thus, inquiry-based activities were emphasized in the course modules. The format is aligned with research-based GCS and state standards for instructional planning and delivery. The major components include (1) goals that are aligned with the North Carolina K-12 Curriculum, (2) activator activities that test students' prior knowledge, (3) teacher input activities in which the instructor teaches new knowledge through demonstrations, (4) an inquiry-based small group activity facilitated by students, and (5) a concluding activity that requires students to reflect on what they learned and share their findings with others. A rubric that is aligned with research-based educational practices was used to evaluate the instructional quality of the module.

\section{Project Design}

The project provided targeted professional development and a research experience for two cohorts of secondary math and science teachers from the GCS Central Region. Project activities included innovative strategies to strengthen educator skills in teaching hands-on NASA-related 
STEM content. Teachers engaged in Earth System Science research under the mentorship of experienced STEM and education graduate students and designed innovative inquiry-based Earth Science teaching modules that are aligned with the North Carolina K-12 Curriculum.

The project activities were designed for sustained implementation over a two year period. Teachers were selected to participate in two cohorts. Cohort A included 20 high school math and science teachers and Cohort B included 20 middle and high school math and science teachers. GCS Central Region math and science teachers selected were full time teachers who teach high school and middle school science and math courses, including earth science, physics, physical science, algebra, geometry, and calculus. During the selection process they

demonstrated that they were highly qualified according to district and state standards, genuinely interested in project activities, and willing to commit to the project beyond the two years of grant funding.

The project had four distinct phases. In Phase One, Cohort A, high school participants, engaged in an intensive summer university experience. While participating in classroom and laboratorybased experiences, they were exposed to cutting-edge research in NASA-Related Earth System Science. In collaboration with university faculty, graduate students and a professional development team of master teachers, Cohort A systematically developed NASA-related STEM K-12 teaching modules for secondary students. The proposed module development activities were designed to help teachers translate their new NASA-related scientific knowledge during the summer research experience into their instructional practices in the classroom.

Cohort A extended their learning during Phase Two. They implemented their newly developed teaching modules at their home schools with direct support from the professional development team. This support included co-teaching, observation, and conferencing. STEM and education graduate students, who were actively engaged with the teachers during many of the summer activities, provided additional support by serving as classroom assistants. M.S., M.A., and Ph.D. graduate students were selectively chosen as those having completed most of their course work so that they would have time to focus on their role in the project. The graduate students received education training during the summer to prepare them to be effective classroom partners with the teachers. Cohort A participants had the opportunity to reflect on their work by attending quarterly teaching and learning seminars.

In Phase Three, Cohort B middle school teachers mirrored most of the activities of high school teachers in Cohort A. The only exception was that each Cohort B participant was paired with a Cohort A teacher. This allowed middle and high school teachers to vertically integrate their modules so that they adequately prepare middle school students for high school math and science content.

\section{Summer Research Institute}

The three-week Summer Research Institute was designed to provide teachers with the experiences outlined above. Lead teachers from the region who had participated in the first Summer Research Institute were interviewed, and provided significant details for the planning of the second year's Summer Institute. Institute participants played a variety of roles. The core participants were 40 secondary STEM teachers. Since one of the major goals was to have 
teachers explore and integrate NASA content and research into their teaching, five graduate researchers at the University level who conducted research based on NASA's work were selected to work with teams of teachers. Each of the five researchers prepared reports specific to their research including video presentation through VoiceThread, PowerPoint slides, written narrative of their research, websites related to their research, and specific curricular standards from the State standard course of study and core curriculum that connected to their research.

Researchers shared responses to prompts such as the connection between their work and NASA, specifically, how they used NASA data in their research, what their research means to them, why K-12 students should care, and what their research would mean to middle and high school students. This information was shared with teachers a few weeks before the Institute. The goal was to demystify the process of research to teachers and students, to show the relevance of STEM research in everyday contexts, and to make STEM problem solving transparent in an engaging way. Based on this shared content, teachers had the option of signing up for one of the five teams based on their teaching commitments, connections to curricular standards, and opportunities for vertical teaming. Some broad topics of research projects included: hurricane prediction, energy efficiency, effects of lightning, gums (probiotics), and emissions. The teams of eight teachers, one STEM graduate student, and one science education graduate student were selected by the first day of the Institute.

All teachers engaged in a collaborative online experience throughout the three weeks using GoogleDocs to start and complete their modules. The modules were taught in the teachers' classrooms after completion of the module development. The teacher teams (two middle school mathematics or science teachers or two high school mathematics or science teachers) completed a total of 20 modules at the end of the three week Institute. The $5 \mathrm{E}$ Inquiry $\mathrm{Model}^{15}$ was integrated into an instructional design for teachers to follow in the module writing process.

A typical day at the Institute started with a one-hour presentation by STEM experts with the goal being to share samples of STEM research in the world. STEM technology workshops based on Web 2.0 technologies were another key component. Teacher participants were presented with specific technologies for approximately two hours each morning. Afternoon professional development sessions were devoted to teams working in separate spaces on their specific modules, with hands-on support from the STEM graduate students and the science education graduate students at the University. This time was also utilized to practice and implement the learned technology into their module writing. In addition, two University faculty members (one faculty in instructional technology and another in mathematics education) worked constantly with the teams. Another science specialist provided some face-to-face training and was available online consistently and provided feedback as the modules were developed. The Institute days concluded with an hour of reflection based on prompts from "The Courage to Teach: Exploring the inner landscape of a teacher's life." 16

\section{Web 2.0 Tools}

Based on STEM content and the educational processes involved in the teaching and learning of STEM content, University faculty and e-coaches (graduate students in the instructional technology graduate program) selected Web 2.0 tools that address many of the STEM learning 
processes such as visualizing, modeling, experimenting, inquiring, designing, collaborating and communicating. ${ }^{11,12}$

Week one focused on immersing teachers in a variety of Web 2.0 tools through fifteen workshops ranging from broad topics such as searching the Internet, Technology Infusion and Inclusion, Interactive Projectors, and Interactive Educational Sites to specific tools such as: Glogster, Prezi, XtraNormal, Moon in Google Earth, Voki, and VoiceThread. Week two explored specific STEM tools such as Seismology and Satellite Imagery Resources and technologies related to mathematics and science fields including current and leading edge calculator functions. Week three provided several STEM Open Labs where teachers could get one-on-one support from e-coaches in a lab setting on the tools that they had integrated in their modules or simply tools that interested them from Week one.

Teachers tested parts of their modules on two mornings with 8-15 learners from their grade levels during the last week of the experience. A total of 60 high school students and 25 middle school students participated in the trial testing of modules. This was a trial run of the modules and the ways in which they integrated technologies. Following this activity, teachers revised their modules. In addition, two high school learners spent approximately three weeks collaborating with the teams providing valuable feedback.

Teachers planned and conducted a four-stage all-day event on the last day based on the theme of 'How Will We Make a Difference in the World?' One of the events was a Glogster Fair that showcased each of the 20 modules (10 mathematics and 10 science) in an auditorium setting with at least 30 laptops that each displayed and demonstrated STEM-related Glogsters that included games, video, and imagesof the three-week experience as well as sections of the modules that they had authored.

\section{Participants and Evaluation Methods}

All 40 teachers were mathematics and science secondary teachers from the same school district and included 13 males and 27 females. Twenty teachers were from middle schools and 20 from high schools. Twenty-one taught science, 15 taught mathematics, and four taught both science and mathematics. Fifty-three percent of the teachers defined themselves as 'digital immigrants' (born before the $80 \mathrm{~s}$ ) and $47 \%$ defined themselves as 'digital natives' (born after the $80 \mathrm{~s}$ ). As part of the evaluation an evaluator developed four surveys for the project participants: a presurvey to assess teachers' familiarity with technology, two interim surveys designed to gather feedback during the professional development, and a summative final survey to assess all teachers' views of the professional development in which they participated.

\section{Web 2.0 Technology Results}

The Technology Pre-survey was administered before the start of the professional development to understand teacher familiarity with certain technologies that they would be introduced to and use during the professional development. As is shown in Table 1, while many teachers utilize PowerPoint and incorporate the use of web materials and inquiry into their lessons, few use wikis, blogs, Prezi, or other programs. In fact, when asked to provide more detailed data (see 
Table 1: Teacher Use of Technology

\begin{tabular}{|c|l|c|c|c|c|c|}
\hline & & Never & $\begin{array}{c}1-3 \\
\text { times/ } \\
\text { year }\end{array}$ & $\begin{array}{c}4-8 \\
\text { times/ } \\
\text { year }\end{array}$ & Monthly & Weekly \\
\hline 1. & I use Powerpoint in my lesson & 0 & 6 & 5 & 11 & 20 \\
\hline 2. & $\begin{array}{l}\text { I use Mobi boards or other } \\
\text { interactive boards in my lesson }\end{array}$ & 20 & 1 & 4 & 7 & 10 \\
\hline 3. & $\begin{array}{l}\text { I integrate the use of web material } \\
\text { (websites, audio, video) in my } \\
\text { lesson }\end{array}$ & 0 & 6 & 4 & 13 & 19 \\
\hline 4. & $\begin{array}{l}\text { I have students explore or search } \\
\text { for information using the web }\end{array}$ & 1 & 10 & 7 & 19 & 5 \\
\hline 5. & $\begin{array}{l}\text { I incorporate the use of wikis, } \\
\text { blogs, prezis, and other programs } \\
\text { into my lessons and student } \\
\text { activities }\end{array}$ & 20 & 10 & 2 & 7 & 2 \\
\hline
\end{tabular}

Table 2), few teachers noted having great familiarity with any of the technologies listed, when asked to rate familiarity on a scale of 1 (Not familiar at all) to 4 (Very familiar).

At the end of week two, teacher ratings to technology related items increased in all four items (Table 3). Ninety-two percent claimed that they had learned multiple technologies that can be used in the classroom. Teacher ratings on all four items actually increased from week one. It is important to note that the ratings on two of the lower items from Week 1 ("My knowledge of technologies and applications we have covered is enough such that I can use them in my class", and "The amount of time spent on STEM Technology workshops has been adequate") increased $17 \%$.

As part of the last day of the professional development, participants were asked to respond to a final survey. As part of this survey teachers were again asked to rate their familiarity with technology. As is shown below (Table 4), teachers were far more positive about their familiarity with technology than when they started the professional development.

The teacher-led last day events included a roundtable session planned and organized by each of the five groups. One of the groups chose a technology activity where they engaged each of the five groups for 20 minutes each, completed a survey, led a discussion, and tabulated results. The survey included a list of all the tools and technologies that the teachers were exposed to during the Institute, and teachers were asked to pick their top three choices as well as to check the ones that they plan to use. In addition, teachers were asked to include ideas for use of those tools. The top three tools were Wordle, Glogster, and Voki, and the most popular were (votes of 20 or more) Animoto, Google Earth, Gaggle, Poll Everywhere, GoogleDocs, and Prezi. In addition, the following were tools that teachers found useful enough to share: 
Table 2: Teacher Familiarity with Web 2.0 Technology (1=not familiar; 4=very familiar)

\begin{tabular}{|l|l|c|c|c|c|}
\hline & & $\begin{array}{c}\mathbf{1} \\
\text { (not familiar) }\end{array}$ & $\mathbf{2}$ & $\begin{array}{c}\mathbf{4} \\
\text { (very } \\
\text { familiar) }\end{array}$ \\
\hline 1. & Google Docs & 28 & 8 & 3 & 3 \\
\hline 2. & Glogster & 38 & 2 & 2 & 0 \\
\hline 3. & Voice Thread & 30 & 10 & 1 & 1 \\
\hline 4. & Voki & 36 & 6 & 0 & 0 \\
\hline 5. & Wikis & 22 & 13 & 5 & 2 \\
\hline 6. & Google Earth & 16 & 10 & 12 & 4 \\
\hline 7. & XtraNormal & 38 & 3 & 0 & 0 \\
\hline 8. & Prezi & 22 & 7 & 6 & 7 \\
\hline
\end{tabular}

Table 3: Comparison of Teacher Ratings of Agreement: Week 1 vs. Week 2

\begin{tabular}{|c|l|c|c|c|}
\hline & & Week 1 & Week 2 & Diff \\
\hline 1. & $\begin{array}{l}\text { The amount of time spent on STEM Technology } \\
\text { workshops has been adequate. }\end{array}$ & $50 \%$ & $67 \%$ & $17 \%$ \\
\hline 2. & $\begin{array}{l}\text { My knowledge of technologies and applications } \\
\text { we have covered is enough such that I can use } \\
\text { them in my class. }\end{array}$ & $58 \%$ & $75 \%$ & $17 \%$ \\
\hline 3. & My questions, if any, have been answered. & $81 \%$ & $86 \%$ & $5 \%$ \\
\hline 4. & $\begin{array}{l}\text { I have learned about multiple technologies that } \\
\text { can be used in the classroom. }\end{array}$ & $87 \%$ & $92 \%$ & $5 \%$ \\
\hline
\end{tabular}

Table 4: Teacher Familiarity with Technology: Final (1=not familiar; 4=very familiar)

\begin{tabular}{|c|l|c|c|c|c|}
\hline & & $\mathbf{1}$ & $\mathbf{2}$ & $\mathbf{3}$ & $\mathbf{4}$ \\
\hline 1. & Google Docs & 0 & 1 & 20 & 13 \\
\hline 2. & Glogster & 1 & 6 & 15 & 12 \\
\hline 3. & Voice Thread & 6 & 16 & 10 & 1 \\
\hline 4. & Voki & 2 & 14 & 15 & 3 \\
\hline 5. & Wikis & 6 & 17 & 7 & 4 \\
\hline 6. & Google Earth & 4 & 10 & 14 & 6 \\
\hline 7. & XtraNormal & 11 & 9 & 11 & 3 \\
\hline 8. & Prezi & 3 & 5 & 14 & 12 \\
\hline
\end{tabular}


- Tagxedo (like Wordle but has pictures too)

- Phet simulation (great simulators for science)

- NASA website (Ready to use lesson plan, videos, resourses, satellite images; webquest)

- Wimba

- Sketchup (create home models; geometry; 3-D models, surface area, angles)

- Keepvid (to save youtube videos on desktop for easy upload or editing)

\section{Web 2.0 Technology Discussion}

As the results indicate, the majority of teachers in the NASA experience more than increased their comfort with and knowledge of Web 2.0 tools. They completed the Summer Research Institute with a shift in their mindset about integrating Web 2.0 tools in their classrooms based on an understanding of how well they tied with their learners and their content. The fact that they were enabled to start with an immersion in the e-coach supported technology workshops, continue with a scaffolded experience in integrating the tools into specific content modules, and then test both content and technology with learners resulted in their own positive evaluations of web 2.0 tools. In fact, the experience resulted in their own leadership in just how the tools could be used by teachers.

Anderson (2008) explains that major affordances of software within the umbrella of web 2.0 with social interaction as a theme are sharing of ideas, resources, and working together or sojourning. Another affordance explained by Sebastion et al., (2009) is the development of social capital. This study showed evidence of the above through both the survey and focus group data. This study also confirms that just knowledge of the tools and technologies that can be used in the classroom is not sufficient for teachers to actually use them in the classroom. After a week's intensive hands-on training in the tools in a lab setting with several e-coaches, teachers agreed overwhelmingly that they now had the knowledge about technologies that could be used in the classroom, but only half claimed that they had learned enough to integrate it into the classroom. The following week, however, $17 \%$ more teachers (or three-fourths) claimed that had received enough training to integrate it in the curriculum. The second week of the Institute focused on engaging the teachers in bringing their content or module writing together with a couple of specific tools such as GoogleDocs and Glogster. Interestingly, these two tools were also ones that teachers claimed they would use in their own classrooms.

Integration of STEM technologies is a complex process for teachers and is grounded significantly in teacher beliefs, ${ }^{10,14}$ but judicious use of formative assessment data during the training, composition of both digital natives and immigrants among the teacher group, immersion in very specific NASA related STEM content, peer mentors, access to e-coaches, opportunities to sample a variety of tools but engage deeply with a few, discussions and reflections on use of tools, and trial testing of tools with learners all proved to be a set of multiple and related factors that multiplied the pedagogical efficacy of the teachers. 


\section{Focus Groups}

Focus groups were conducted with 37 current project teachers as part of the third week of professional development. The purpose of the focus groups was to gather feedback about teachers' experiences to date as part of the Summer Research Institute. The project evaluator and a colleague facilitated five focus groups which lasted approximately 45 minutes each. Teacher participants were broken into groups of ten by school level (middle and high) with 2 focus groups conducted simultaneously per school level. A total of 8 graduate students, including both researchers and graduate students participated in a separate focus group.

Teachers were first asked to rate on a scale of 1 (low) to 5 (high) their experiences to date as part of the Summer Research Institute. Middle school teachers rated their experiences slightly lower than high school teachers, most of who were participating for the second year. (All middle school teachers were new to the project this summer). The average rating provided by middle school teachers was 3.83 with the average rating provided by high school teachers slightly higher at 4.1 .

Next, all teachers were asked to explain their ratings by noting what had been particularly positive. Middle school teachers noted such things as "learning new technologies", "collaborating with A\&T researchers and education specialists" and "working with the high school teachers". One teacher noted that, "taking different content and putting it into your classroom - like how to implement science in a math classroom" was a very positive experience and that it had provided her, "different ideas I can take back to the classroom".

High school teachers noted many of the same positive aspects of the Summer Research Institute as the middle school teachers, including that they had more time this year to develop their modules, that both graduate researchers and education graduate students "seem more familiar with their roles this year" and thus were more integrated into module development, and that the professional development was "better organized" and that such organization provided greater guidance for organizing their modules. They also appreciated knowing what topics they would be covering each day as it related to learning technology and STEM in general.

Unlike middle school teachers, high school teachers were very positive about having picked their topics before the start of the professional development and that they could pick topics based on their interest, as opposed to the group's interest as was the case last year. Middle school teachers, on the other hand, wanted more time to understand the topics and didn't like having to pick topics at 11:55 on a Sunday night. They wanted all researchers to present more in-depth about their tropics when they met with them in May. They also pointed out the restrictiveness of topics for certain grades in the middle school curriculum. "All the topics applied to the $7^{\text {th }}$ grade curriculum, but only certain ones would fit the $6^{\text {th }}$ and $8^{\text {th }}$ grade curriculum."

Both middle and high school teachers were generally negative about "reflections" and wanted that time better used to address questions that had arisen throughout the day, to work on modules, or to go home. None saw the connection between reflections and module development and many felt that reflections were "not authentic" to what they were doing. On the other hand, all teachers believed that the time that they spent in the computer labs learning various technologies was time well spent. Many were very positive about the e-coaches although some 
wanted lab attendants who better knew the technologies to which teachers were being introduced. Teachers noted that they had incorporated these new technologies into their modules "and tried to not just put it in but to use technology to enhance what we are doing in the module". Specific examples included using Glogster as way to get students to share their views about global warming and using ExtraNormal as an introduction to a lesson to better engage students. Other teachers talked about how much more familiar they were with Google Docs as a result of the fact that all information they needed was available to them via this platform and how they loved using Google Docs to collaborate with module team members. As one high school teacher commented, "I really enjoyed the technology - there's so much that I learned in the workshops that I can take back to my class. Also kids were really into the technology that they will get to use." However, there was a concern that schools will not receive approval for access to restricted sites in a timely manner to allow teachers to actually use some of the technology with their classes and as part of their modules. Recommendations for improving the technology labs was to "provide a graphic organizer" and to begin the modules earlier so that teachers would "have a framework" to help navigate and consider in concrete ways, how to use the many technologies that were introduced.

\section{Mentoring by High School Teachers}

From middle school teachers' viewpoints, mentoring by high school teachers was somewhat hit or miss although many noted that when asked, high school teachers were more than willing to help. High school teachers also recognized this and noted that they were not clear about what the expectations were for them as mentors. Some high school teachers did share last years' modules that they developed with middle school teachers, but as the template for modules was different this year they were not sure how helpful such sharing was. As one high school teacher commented, "Our role was to help middle school teachers - teach them how - but needed to be stated - more obvious to both of us. I have not really helped them but point out 5Es." Another noted, "We took our middle school people through a module from last year. But it wasn't explicit that we were supposed to do this. (They) said we were mentors but expectations weren't clear." Middle school teachers felt that a general orientation would be helpful for them, rather than depending solely on the high school mentors to individually take on that role. They also recommended specific instruction on "how to write a module".

\section{Graduate Student Focus Groups}

The graduate students focus group included 5 research students (two in their second year with the project) and 3 graduates from the School of Education (one of whom worked with the program last year.)

As graduates described how and why they became involved in the program, most expressed appreciation for the learning experience that it provided them. Several of the graduates - both research and education - spoke of how "the teachers learn from us and we learn from them". Researchers felt it was "important for teachers to connect with someone who does science" and to encourage students' interest in "becoming researchers" by engaging in the research-based lessons that participating teachers prepared. One researcher described how he had "bonded with the students" as he presented at one of the high schools and "wanted to give more." Education graduates appreciated seeing "how veteran teachers think in creating lesson plans" and researchers with teaching aspirations "learned a lot by being around the educators and the 
students" who came to participate in the lessons teachers had developed. Also important to many of the graduates was the stipend in the form of tuition credits. As one graduate described how important that support has been for "finishing his program", another graduate agreed that "it is a stimulus (for participation) for each of us" and others nodded in agreement.

As with the teacher participants, graduates were asked to rate on a scale of 1 (low) to 5 (high) their experiences to date as part of the Summer Research Institute. Their average rating of 4.0 was most similar to the ratings of the high school teachers. Explaining their positive ratings, several graduates cited the opportunity to learn from the e-coaches and the guest speakers. One, for example, described the technology workshops as "very interesting" and an introduction to many tech-based strategies that "I can do for myself in my own work". One research student found "the teaching part," "inquiry-based learning" and the "Texas Instrument speaker" particularly positive; another found it gratifying to see the "teachers got it (the research)" and "pulled from it" in their module development. One returning graduate was "proud of the math teachers". In contrast to how they had "struggled last year" the graduate said " the creativity of math teachers this year was awesome". Another graduate added that "the way they expressed math to students was amazing.

Graduates' descriptions of less positive aspects of the Institute were very similar to the teachers' responses, with a focus on the reflection time at the end of the day and the modules template. Graduates thought the "reflections were too long". They described the module template as "vague", "repetitive", and much too long- "they were many pages". Graduates felt unprepared to help teachers. Because they had not received advanced exposure to the template, they "were learning with the teachers". Their advice to teachers - similar to what returning high school teachers said-was to "focus on the 5 E's".

Graduates' roles in module development included addressing questions from teachers about the research; assisting them in understanding expectations for the modules and integrating technologies; and for one, reviewing the lesson plans, at a teachers' request. As noted, graduates enjoyed working with the teachers. While second year graduates felt more engaged and involved this year, some still would have liked "a more active role", particularly in the second week when they were "here all day" but "not as needed". One suggested that perhaps "something more hands-on with the researchers" could be done "during the reflection time" in the schedule. Another would like to have had more e-coaches to better assist the roomful of teachers who were "like chirping birds in a nest" as they called for help with the technologies. Graduates also expressed appreciation for the "cohort A" teachers who "could help with answering questions" from the in-coming group and could also share sample modules from last year.

\section{Student Evaluation Methods}

To better understand what impact teachers' NASA and earth science-related modules have on students understanding of, and interest in NASA research, a student survey was developed that asked about these and other impacts. Participating teachers who had implemented modules in their classroom were asked to survey their students within two weeks of implementing modules to gather students' responses. Teachers were also surveyed and asked to reflect on their modules including what impact they think it had on students and in what ways it could be improved. Surveys were sent to teachers during the month in which they implemented their modules and 
included instructions for surveying and all student surveys. A total of 421 students across 5 schools and multiple grades $(6,7,9,10,11$, and 12$)$ responded to the survey. The nine teachers who surveyed their students were also surveyed and asked to reflect on their modules, including what impact they think it had on students and in what ways it could be improved. The mathematics courses represented included Advanced Functions \& Modeling, Algebra II, Bridge Math 2, and Technical Math 2. Science courses include Chemistry and General Science.

\section{Student Results}

Findings to date include the following points. Students found the relevant, hands-on, and inquiry nature of modules refreshing and meaningful. On average, students reported that modules most strongly impacted them in terms of:

-making math/science seem more useful in the real world (mean 3.83, $\mathrm{sd}=1.18$ );

-making math/science more fun (mean $=3.71$, sd $=1.28)$; and

-increasing their knowledge of what people do at NASA (mean 3.71, sd $=1.21$ ).

Teachers too could tell how modules had impacted students, although they rated impacts slightly higher than students. Teachers rated their module impacts at or above 4.11 with respect to:

-making math/science more fun (mean 4.67, sd $=.50$ );

-making math/science seem more useful in the real world (mean 4.33, sd=1.12);

-making students more interested in how math/science are used outside of the classroom (mean $=4.2, \mathrm{sd}=.667)$; and

-helping students see connections between math/science and NASA research $($ mean $=4.11, \mathrm{sd}=$ 1.05).

Students rated modules as having the least impact in terms of their interest in NASA in general or jobs or careers that use NASA research. Although students reported that modules least impacted their interest in NASA in general or jobs or careers that use NASA research (29\% rated this a 4 or 5 on a scale of 1 (Not at all ) to 5 (To a great degree)), these findings need to be weighed carefully against the fact that not all students are interested in math or science careers, and that of those, not many will be interested in the work specifically of NASA. In fact, in comparison, findings indicate that $40 \%$ of students provided ratings of 4 or 5 to the statement "To what degree did modules interest you in jobs or careers that use math and/or science".

Science modules were rated slightly higher than math modules. It is not clear whether this finding may be a function of the actual module, or could be a function of the subject area and/or trying to link science research to mathematics classes. Thus it may be important to hear more from math teachers about their Summer Institute experience and needs they may have to better link NASA research to mathematics classes.

Results suggest that students related well to the relevancy, inquiry, and hands-on nature of the modules in which they participated, and that modules helped them see connections among math and science and the real world, made math and science more fun, and increased their knowledge of what people do at NASA. Although students reported that modules least impacted their interest in NASA in general or jobs or careers that use NASA research (29\% rated this a 4 or 5 
on a scale of 1 (Not at all ) to 5 (To a great degree)), these findings need to be weighed carefully against the fact that not all students are interested in math or science careers, and that of those, not many will be interested in the work specifically of NASA. In fact, in comparison, findings indicate that $40 \%$ of students provided ratings of 4 or 5 to the statement "To what degree did modules interest you in jobs or careers that use math and/or science".

Not surprisingly, teachers' ratings of impacts on students were slightly higher than students' actual ratings, as shown in Figure 1. However, teachers' ratings in general mirror those of students, suggesting that teachers were able to accurately assess areas in which modules impacted students.

Figure 1. Comparison of Student and Teacher Ratings

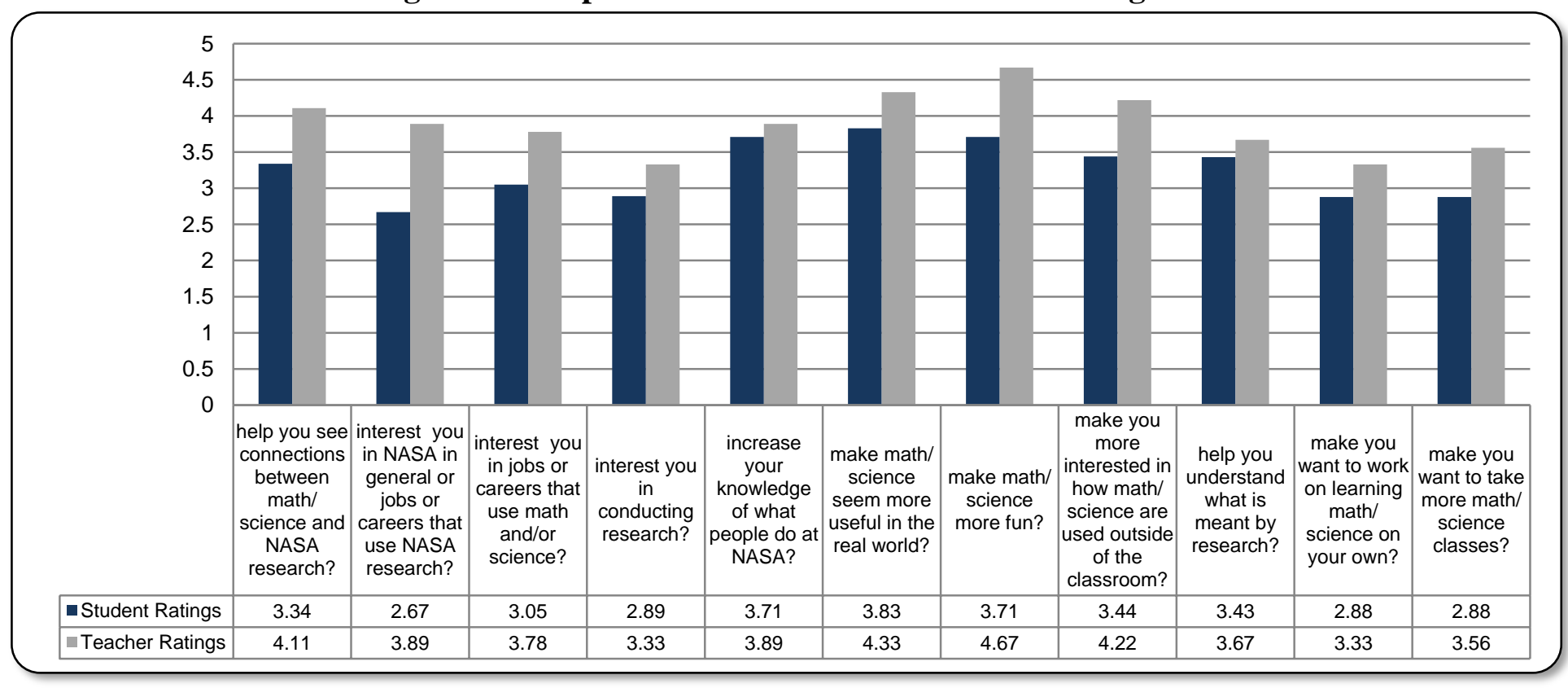

\section{Conclusion}

Taken together, findings from the various evaluative activities indicate that the summer research experience was well received by participants. For example, teachers were positive about the professional development that they were provided, with $89 \%$ of the 34 teachers participating rating it a 4 or 5 on a scale of 1 (Poor) to 5 (Great) in Week 2, an increase of $10 \%$ from the week before. By week 2 teachers were also more positive about multiple aspects of the professional development, including

-Being more familiar with what is meant by 'inquiry;

-The amount of time spent on STEM Technology workshops; and

-Their knowledge of technologies and applications such that they could use them in their class.

When asked at the end of the professional development about the level of support provided to them, teachers were very positive that they had been provided time to develop curricula models, support for using inquiry, and support for utilizing their research experience as a basis for their 
curricula. However, they were less positive about the support provided for including formative assessment in their curricula and in terms of direction for what their modules should look like.

Final survey responses also revealed that teachers were much more familiar with multiple technologies, most notably Google Docs and Glogster. In fact, many teachers' responses throughout the multiple surveys about what they liked best was about learning new technology and how to integrate it into their curricula and classes. Qualitative data suggest that while teachers did struggle with what their modules should look like, quantitative data suggest that they were given enough time to work on modules. Qualitative data further indicate that the use of last years' teachers as mentors was very helpful, especially as it related to developing modules.

Suggestions for improving modules include making them as inquiry-based, hands-on, and as relevant as possible, and providing more time for students with the modules as solid inquirybased pedagogy requires. Providing Summer Institute teachers a chance to see a completed module that has been shown to have been successful with students might also help teachers see what is meant by "module" and open their eyes to additional possibilities. As the math modules that were conducted to date appear to have been received by students less well than the science modules, it may be important to hear more from math teachers about their Summer Institute experience and needs they may have to better link NASA research to mathematics classes.

\section{Acknowledgements}

Enhancing Earth System Science Education in Guilford County Schools Central Region is supported by a grant from the National Aeronautics and Space Administration, award number 09-2009-K12-0097.

\section{References}

1. Banilower, E.R., Boyd, S.E., Pasley, J.D., and Weiss, I.R. (2006). Lessons from a decade of mathematics and science reform: A capstone report for the local systemic change through teacher enhancement initiative. Chapel Hill, NC: Horizon Research.

2. Donovan, M.S., Bransford, J.D., and Pellegrino, J.W. (1999). How People Learn: Bridging Research and Practice, National Academy Press, Washington, DC.

3. Felder, R.M., and Silverman, L.K., "Learning and Teaching Styles in Engineering Education," Engineering Education, 674 (1988).

4. Marzano, Robert J., Pickering, Debra J. \& Pollock, Jane E (2005). Classroom Instruction that works: Research-based strategies for increasing student achievement. Upper Saddle River, New Jersey: Pearson Education, Inc.

5. National Research Council. (2008). NASA's Elementary and Secondary Education Program: Review and Critique. Committee for the Review and Evaluation of NASA's Precollege Education Program, Helen R. Quinn, Heidi A. Schweingruber, and Michael A. Feder, Editors. Board on Science Education, Center for Education. Division of Behavioral and Social Sciences and Education. Washington, DC: The National Academies Press.

6. Rosenberg, S.L., Heck, D.J., and Banilower, E.R. (2005). Does teacher content preparation moderate the impacts of professional development? A longitudinal analysis of LSC teacher questionnaire data. Prepared for the National Science Foundation by Horizon Research, Inc.

7. Supovitz, J.A., and Turner, H.M. (2000). The effects of professional development on science teaching practices and classroom culture. Journal of Research on Science Teaching, 37, 963-980.

8. U.S. Department of Education, What Works: Research about Teaching and Learning. Washington, DC: U.S. Department of Education, 1986. 
9. Anderson, T. ( 2008). Social software technologies in distance education: Maximizing learning freedom. In E. T. M. Haughey \& D. Murphy ( Eds.), International handbook of distance learning ( pp. 167-184). Bingley, UK: Emerald.

10. Bransford, J. D., Brown, A. L., and Cocking, R. R. ( Eds.). ( 2000). How people learn: Brain, mind, experience, and school. Washington, D. C.: National Academy Press.

11. Howland, L.J., Jonassen, D., \& Marra, M.R. (2012). Meaningful learning with technology. Boston, MA: Pearson Education Inc.

12. Maloy, R. W., Verock-O'Loughlin, R.-E., Edwards, S. A., \& Woolf, B. P. (2011). Transforming learning with new technologies. Boston: Pearson Education.

13. Sebastion, V., Namsu, P., \& Kerk, F. K. ( 2009). Is there social capital in a social network site?: Facebook use and college students' life satisfaction, trust, and participation. Journal of Computer- Mediated Communication, 14( 4), 875-901.

14. Wozney, L., Venkatesh, V., \& Abrami, P. ( 2006). Implementing computer technologies: Teachers' perceptions and practices. Journal of Technology and Teacher Education, 14( 1), 173- 207.

15. Bybee, R., Taylor, J. et al. (2006). The BSCS 5E instructional model: Origins and effectiveness. Colorado Springs, CO: BSCS.

16. Palmer, P. (1997). The Courage to Teach: Exploring the inner landscape of a teacher's life. Hoboken, NJ: Jossey-Bass. 